\title{
FLOW OBSERVATION BY ROD LENS AND LOW-LIGHT VIDEO (VIDEOTAPE SCRIPT: JANUARY 4, 1977)
}
D. E. Lord
G. W. Carter
R. R. Petrint

August 10, 1977

Prepared for U.S. Energy Research \& Development Administration under contract No. W-7405-Eng-48

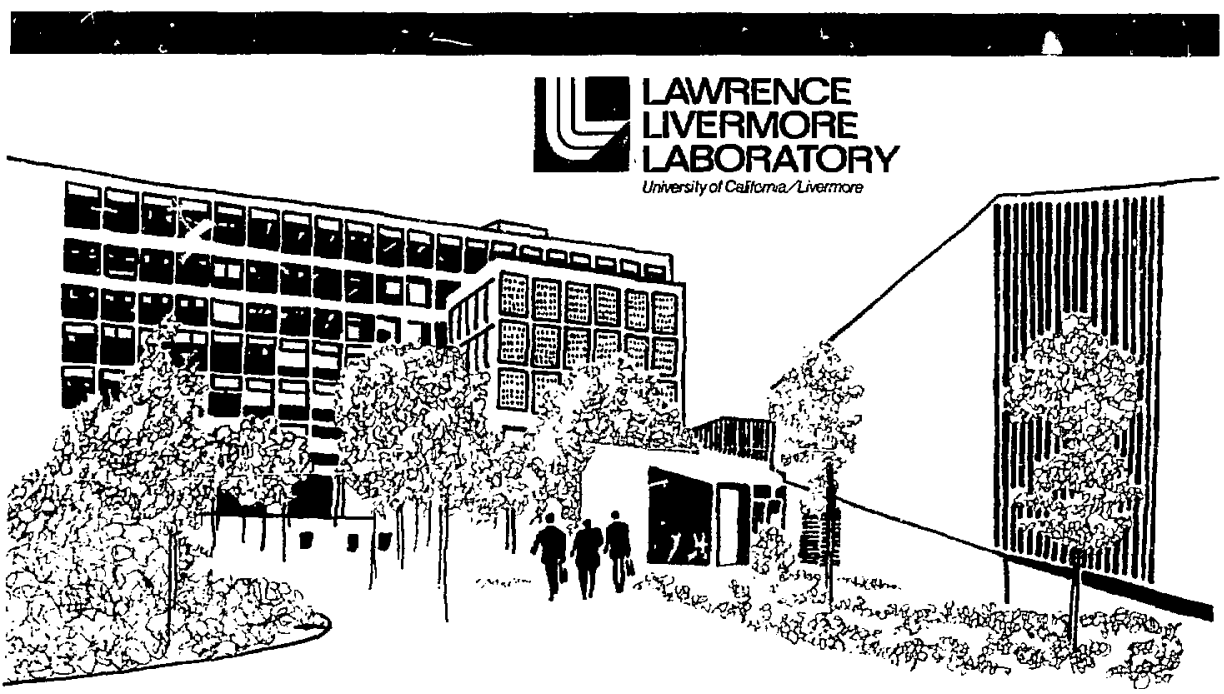




\section{NOTICE}

"This report was prepared as an account of work sponsored by the United States Government. Neicher the United States nor the United States Department of Energy, nor any of thei: employees, nor any of their contractors, subcontractors, or their employees, makes ary warranty, express or implied, or assumes any legal liability or responsibilty for the accuresy, completeness or usefulness of any information, opparatus, product or process disclosed, or represents that its use would not infringe privately-owned dights."

\section{NOTICE}

Reference to a compony or product name does not imply approval or recommendation of the product by the University of Colifornia or the U.S. Department of Energy to the exciusion of others that may be suitable.

Printed in the United States of America

$$
\text { Available from }
$$

Nationat Technical Information Service

U.S. Department of Commerce

5285 Port Royal Road

Springfield, VA 22161

Price: Printed Copy 5 ; Microfiche $\$ 3.00$

\begin{tabular}{|c|c|c|c|}
\hline Page Range & $\begin{array}{c}\text { Domestic } \\
\text { Price }\end{array}$ & Page Range & $\begin{array}{c}\text { Domestic } \\
\text { Price }\end{array}$ \\
\hline $001-025$ & 54.00 & $326-350$ & $\$ 12.00$ \\
\hline $026-050$ & 4,50 & $351-375$ & 12.50 \\
\hline $051-075$ & 5.25 & $376-400$ & 13.00 \\
\hline $076-100$ & 6.00 & $401-4 ? 5$ & 13.25 \\
\hline $101 . .125$ & 6.50 & $426-450$ & 14.00 \\
\hline $126-150$ & 7.25 & $451-475$ & 14.50 \\
\hline $151-175$ & 8.00 & $476-500$ & 15.00 \\
\hline $176-200$ & 9.00 & $501-525$ & 15.25 \\
\hline $201-225$ & 9.25 & $526-550$ & 15.50 \\
\hline $226-250$ & 9.50 & $551-575$ & 16.25 \\
\hline $251-275$ & 10.75 & $576-600$ & 16.50 \\
\hline $276-300$ & 11.00 & 601 up & $\ldots$ \\
\hline $30 t-325$ & 11.75 & & \\
\hline
\end{tabular}

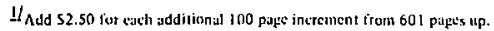




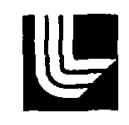

\title{
LAWRENCE LNERMORE LABOFATORY
}

University of Caltornia/Livermore, Calitornia/94550

\section{UCRL-52324 \\ FLOW OBSERVATION BY ROD LENS AND LOW-LIGHT VIDEO \\ (VIDEOTAPE SCRIPT: JANUARY 4, 1977)}

\author{
D. E. Lord \\ G. W. Carter \\ R. R. Petrini
}

MS. date: August 10, 1977

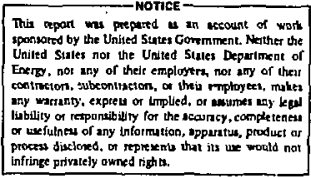




\section{FLOW OBSERVATION BY ROD LENS AND LOW-LIGHT VIDEO (VIDEOTAPE SCRIPT: JANUARY 4, 1977)}

\section{ABSTRACT}

This report presents the script of a demonstration videotape made to show the possibilities of coupling rod lenses to low-light video systems to observe internal flow conditions. The fllustrations accompanying the text were photographed directly from the video screen. Some updated comments appear as footnotes to the original script and a description of the multiscan low-11ght television system developed to meas- ure velocity is included in the epilogue. The combination of rod lens and low-light video system makes it possible to observe dynamic events in hitherto inaccessible volumes. The pressure and temperature capabilities of the rod lens make it applicable to many engfneering uses. This system, in conjunction with electronfc image enhancement systems, provides a new dimension in engineering analysis.

\section{PROLOGUE}

The rod lens is a long cylindrical optical system with a small cross section. It can be as small as $1 \mathrm{~nm}$ in diameter and $10 \mathrm{~cm}$ long or as large as $2.5 \mathrm{~cm}$ in dfameter and $10 \mathrm{~m}$ long. These lenses are not fiber optic bundles; they are solid lenses arranged in different configurations. Most have a built-in bundle of glass fibers that transmit light to the object. They may also be used with other illumination. Because of these
Innovations, the modern rod lens provides brilliant images by keeping Internal light losses to a minimum.

Although the rod lens is an improvement over the borescope, under most conditions it does not transmit en ough light to record dynamic events. Therefore, we thought a low-lightlevel TV camera with a 40,000 light gain coupled to the rod lens would provide the extra sensitivity necessary for dynamic conditions while 


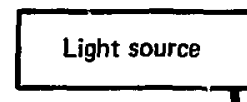

\section{Fiber bundle}

Rod lens
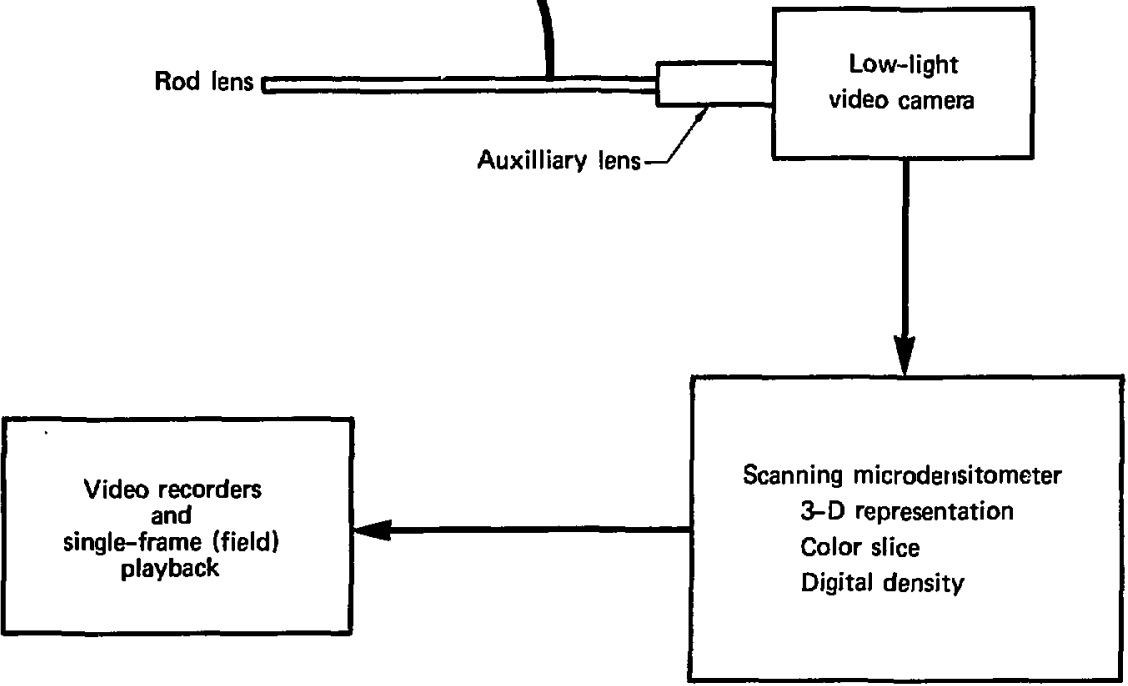

Fig. 1. Endo/optronics analysis system.

retaining the geometrlc access advantages of the rod lens. The system also includes a conventional video recording and single-fleld playback capab111ty (Fig, 1).

Lawrence Ifvermore Laboratory (LLL) first trled the system in the fall of 1976 on a two-phase flow system. He were able to directly observe the turbine/drag-bar-type flow-measuring instrumentation. The rod lens system showed lack of mixing as the reason for the apparent malfunction of the test section instrumentation.
We then demonstrated the rod lens on a $1 / 5$ scale model of a Mark I Bolling Water Reactor pressure suppression system ( $2-m$-dlameter) for the Nuclear Regulatory Commisston (NRC). The LLL plan called for highspeed cameras and large access windows. We felt the video system would be complimentary and even advantageous because of its Instantreplay capability and ability to immediately single-frame (fleld) the results. We also suggested a three-camera grouping for optimum 
observation. Both hIgh-speed cameras and video systems are used.

The NRC requested that we demonstrate the system with possible applications to reactor safety monitoring. We did this by building a pize rest section and observing various flow concitions within it and then recording the results on videotape. This report is the updated script of that videotape with photographs made directly from the video screen. It is provided mainly for those people who expressed an interest in the subfect matter but who do not have facilIties for videotape presentations. 


\section{VIDEOTAPE SCRIPT}

The purpose of this tape is to communicate and demonstrate the uses of the rod lens in conjunction with low-1ight-level television systems. Our Imediate use is pressure suppression testing for the Nuclear Regilatory Commission at LLL.

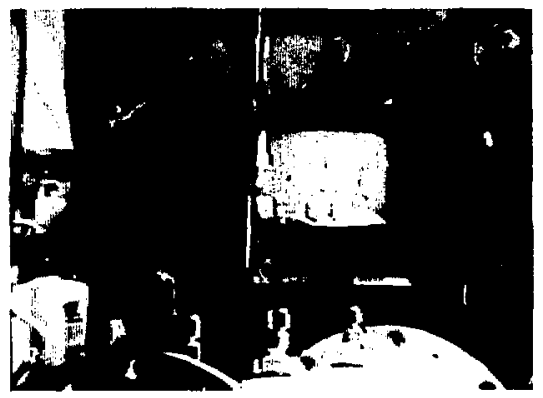

Fig. 2

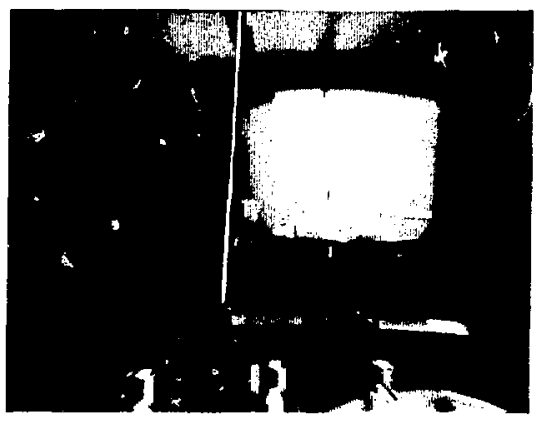

Fig. 3

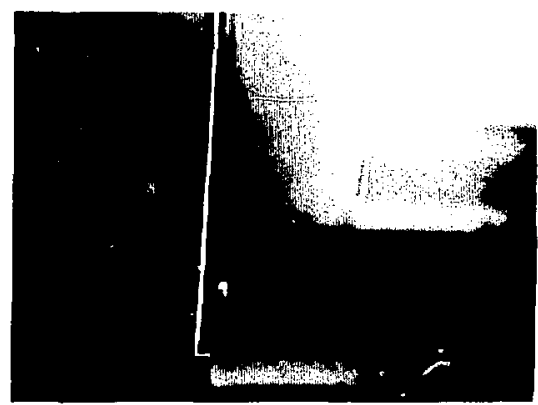

Fig. 4 
The system offers Instant-replay capability and the rod lens can be Introduced into plpes through standard tubing fittings (Figs, 5, 6, 7), where observation windows or glass pipe sections are not practical or even possible. It also affords unlimited angles and magnification of observation tot possible with windows as well as non-fogging operation.

The rod lens is a British patent of Professor Hopkins and is manufactured In Germany; the Japanese also manufacture sinilar systems.

The light transmission properties of a rod lens are further enhanced and made applicable to dynamic flow conditions by a low-light-level TV camera of USA manufacture with a light gain of 40,000 times. The particular rod lens system we use has a bundle of glass fibers built into the OD of the rod to carry light from an illumination source to the object. Reflected light is returned through the rod lens system not the fiber bundle.

This tape is divided into 4 segments:

1. The fixture used to test flow conditions.

2. Examples of what can be seen Inside the plpe.

3. Analytical measurements.

4. Present 1imitations and future improvements.

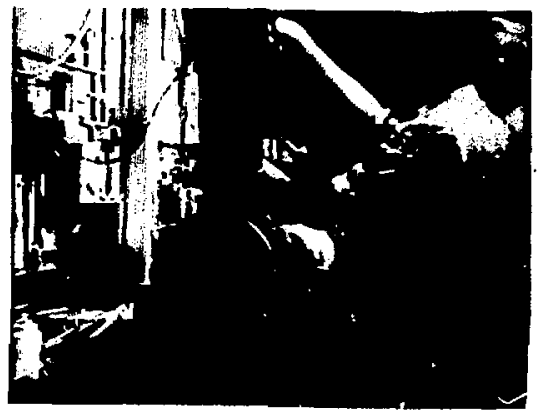

F1g. 5

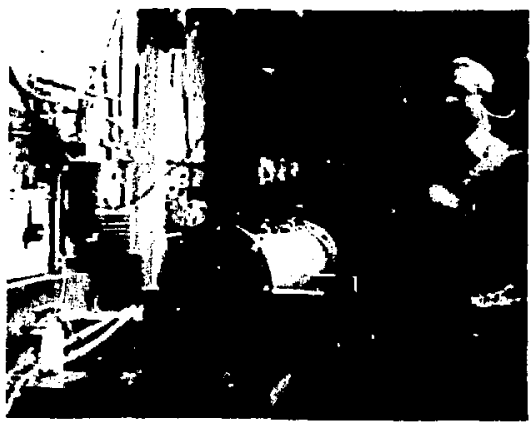

Fig. 6

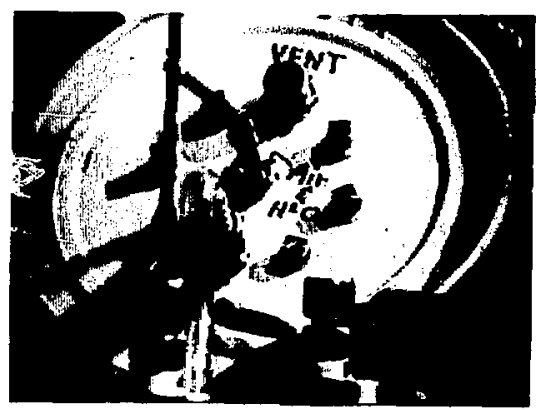

F1g. 7 
The fixture you have been watching in assembly is a 1-m-long section of plpe about $200 \mathrm{~mm}$ in alameter (Figs. 8, 9). In is designed to be about one-third filled with water and to handle simultaneous Jiquid and vapor flow. The liquid part is fitted with an immersion heater and is also used as a reservolr of hot water which can be sprayed into the top or vapor section of the pipe by the simple alr-operated T-section pump. Droplet size can be regulated by alr pressure and liquid line construction. The rod lens is introduced into the pipe section through standard tubing pressure fittings. In this case we also introduce two thermometers through the additionai. fittings to monitor 1iquid and vapor temperatures. Here we use a $90^{\circ}$ rod lens which allows $360^{\circ}$ rotation and $360^{\circ}$ observation. It can also be moved vertically to examine underwater conditions, subsurface, above surface, and vapor flow conditions.

The test section is assembled and the Internal view checked by rotating the lens (F1g. 10).

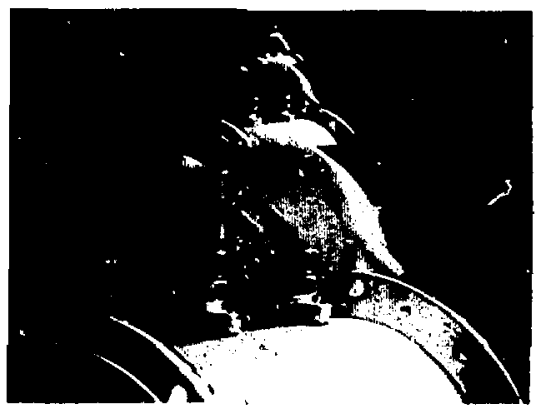

F1g. 8

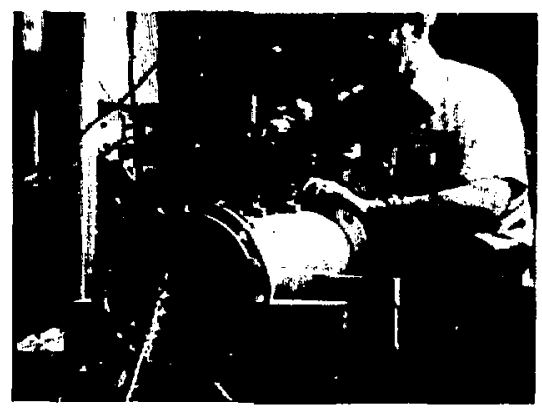

F1g. 9

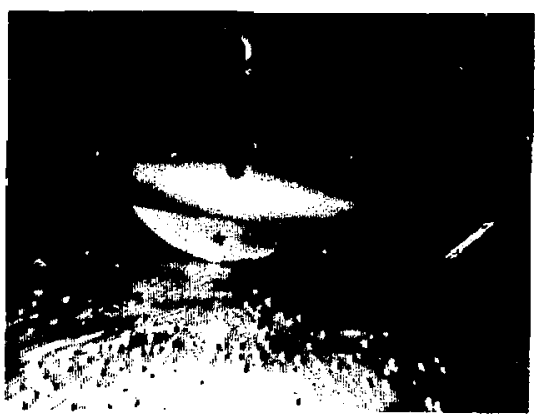


The Immersion heater and internal features are well 11 luminated and can be observed in detail (Fig. 11).

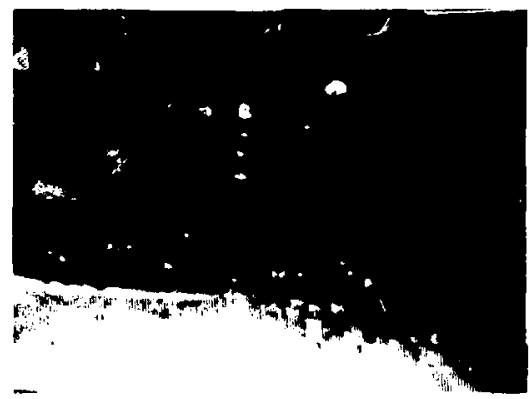

F1g. 11
Now the $54^{\circ} \mathrm{C}$ water is admitted note the change in index of refraction and the reflection from the overhead water surface.

The vertical position of the lens is raised and we observe the surface film and the vapor above it (FIg. 12). As air flow and droplet spray are introduced the vapors increase and take on the appearance of a snowstorm (Fig. 13).

We have added a lens between the rod lens and the TV camera. This gives us a two times magnification and allows us to fill the TV screen. Ordinar1ly, because of the tremendous depth of field of the rod lens such additional lenses are not necessary. However, this additional lens also allows us to choose our depth of fleld and subsequently the features we wlsh to observe.

Here (FIg. 13) we are observing convective vapor flow above the surface of the water.

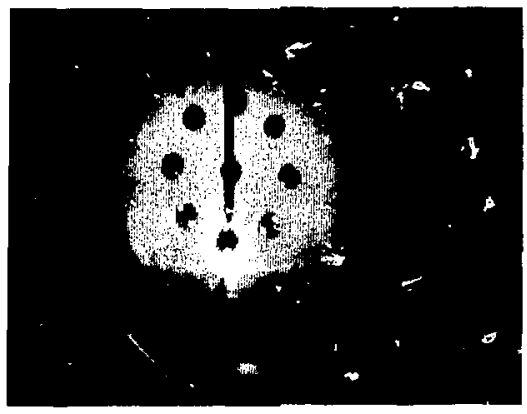

Fig. 12

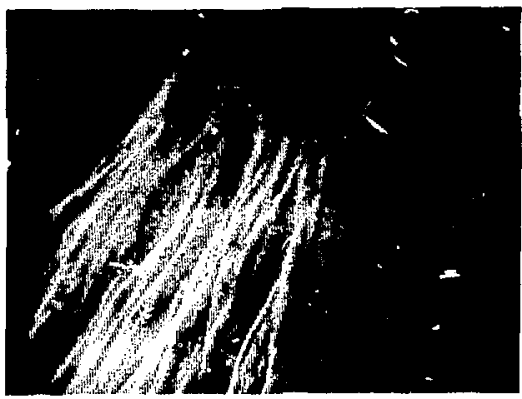

Fig. 13 
Th1s short sequence (Figs. 14-18) again shows some Interesting efferts as we break the surface. The temperature is $90^{\circ} \mathrm{C}$. Again we go from underwater to breaking the surface to vapor flow. Note the relative calm of the underwater condition compared to the convective violence of the vapor phase.

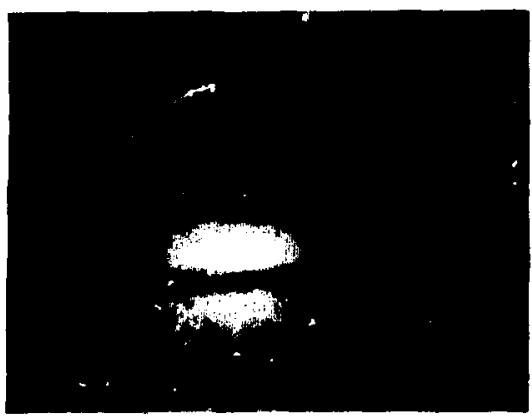

F18. 16

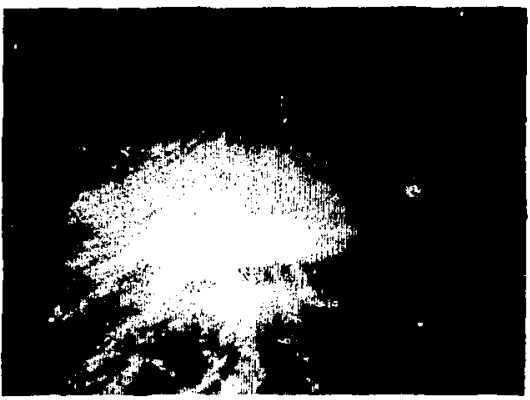

Fig. 17

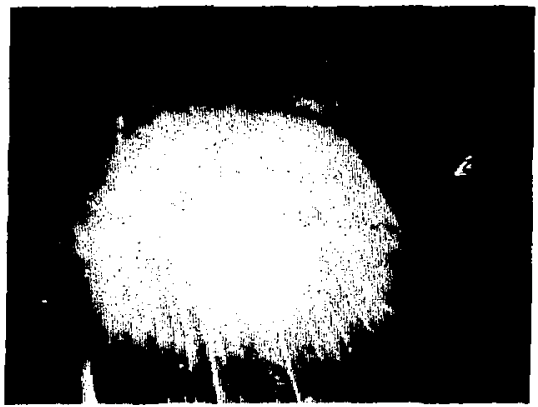


Here we have vapor flow, blown by alr, at shallow depths of fleld (F1g. 19). As we change the depth of fleld the end plate of the test section comes into sharp view and the vapor droplets tend to blur out (Figs. 20, 21). Note that as the depth of fleld Increases the vapor becomes very transparent. It is worth noting that there is a relationship between steam quality and opacity that can be exploited by electronic/ optical analysis. Now we return to the shallow depth of fleld (FIB. 22).

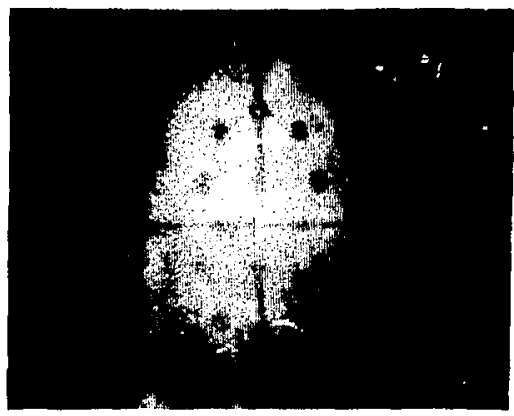

Fig. 21
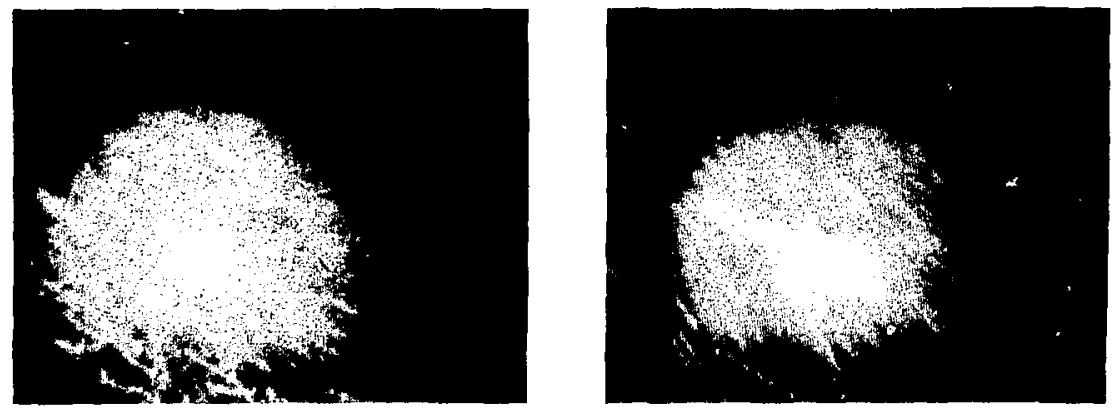

Fig. 19

Fig. 22 
Below the surface, a look at the Immersion heater gives us an Idea of the nucleate bolling process ( $\left.F 1_{\mathrm{g}}, 23\right)$. Bulk temperature of the water here is $90^{\circ} \mathrm{C}$. Normal continuous operating temperature of the standard rod lens is $180^{\circ} \mathrm{C}$. We have used them in short-time applications, however, to $350^{\circ} \mathrm{C}$. The hot spots on the heater are evident as is the convective flow around 1t. The larger vapor bubbles cling to the cooler reglons.

Here we're observing some of the snowstorm produced by air-blown water vapor (FIgs. 24, 25, 26).

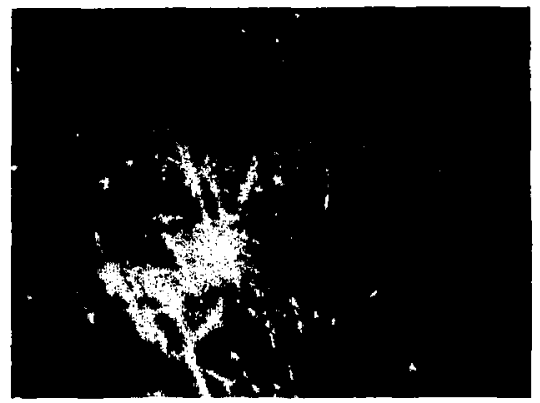

FIg. 24
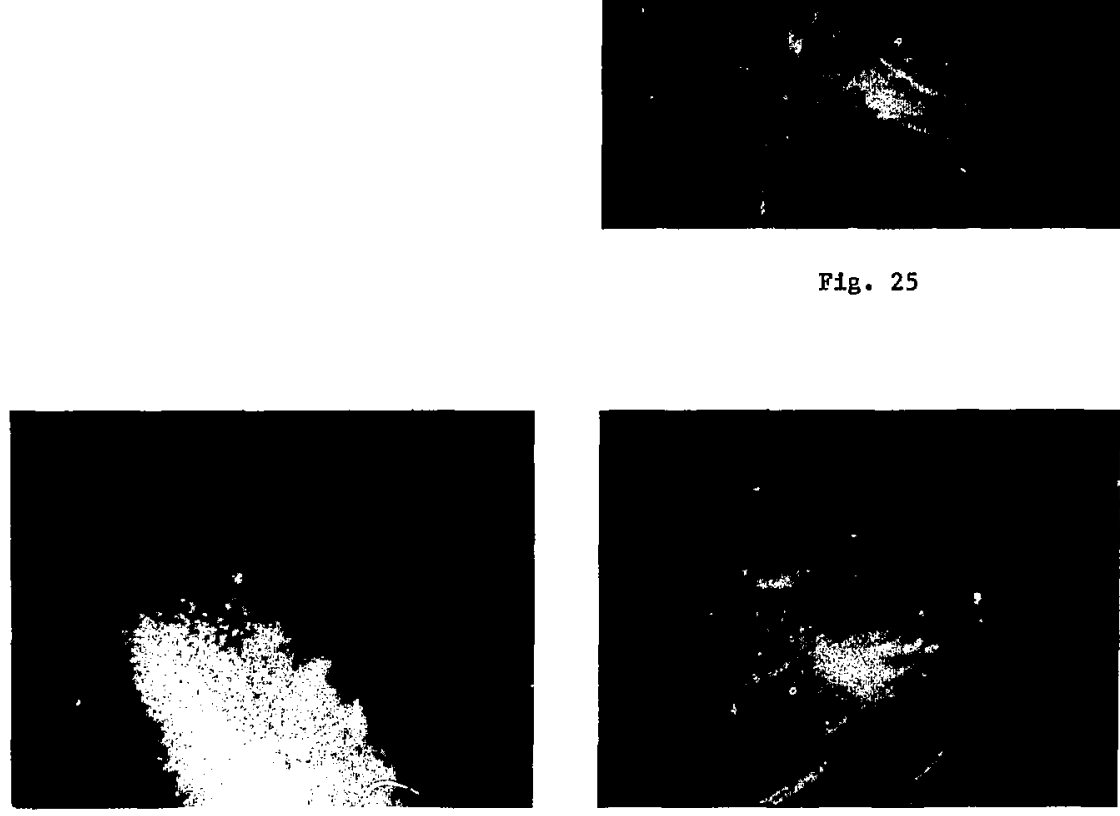

Fig. 26 
There are several ways to analyze the results of the flow systems you have seen. The first and simplest is to practice single framing or slow framing to measure the bubble or droplet size and its velocity (Figs, 27, 28). The events must be slower than the TV scanning rate to achleve "stop action" measurements.

This section illustrates some of the several flow experiments we have conducted. In some we have gone to different backgrounds to help contrast. In most you can recognize the blurred Image of the end cap of the pipe section in the background.

In order to size particles with reasonable accuracy it is necessary to calibrate the field volume of view through the system. This can be done whth precision grids at different: positions within the view volume.

There is another method of velocity measurement that is tied to the scanning speed of the TV system and is generally referred to as "measuring the head of the comet." Measuring the tail of the comet, the

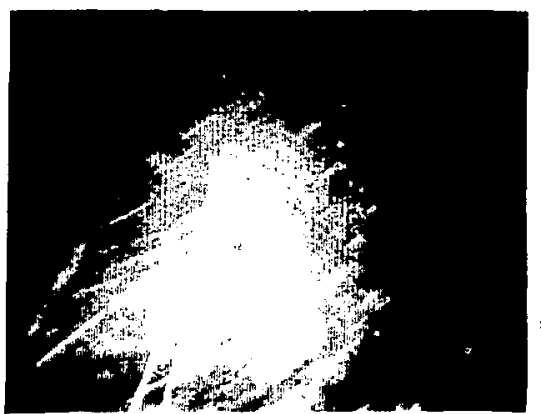

Fig. 28 TV screen and camera retention, gives us the trajectory of the particle. The angle of the head of the comet, the brightest line segment, with respect to the TV scan lines gives us an Idea of the particle veloctty that produces that bright Iine. This comes from a single particle interacting with the $I V$ scan system and 
is analogous to photographing aerial fireworks or stars at slow shutter speeds.

It is easter to measure such velocities if we can keep the bright comet heads at uniform Intensity and size Indicating motion primarily in the $x-y$ plane. The rod lens can be angled perpendicularly to the primary flow pattern to produce such effects.

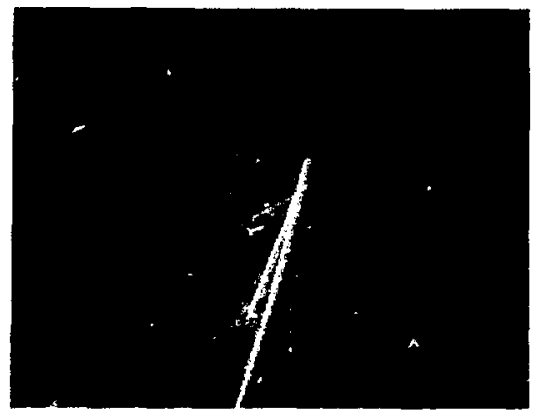

F18. 29

Most of the vapor droplets in this tape fall In the 10 - to $50-\mu m$ range. Velocity measurements are 1 imited to maximum 10 to $100 \mathrm{~m} / \mathrm{s}$ depending on the angle of observation and its relationship to the scan of the $\mathrm{TV}$ Bystem.

These techniques are developmental but have already been demonstrated as feastble.

Here are some examples of slow framing of flow conditions (FIgs. 29, 30).

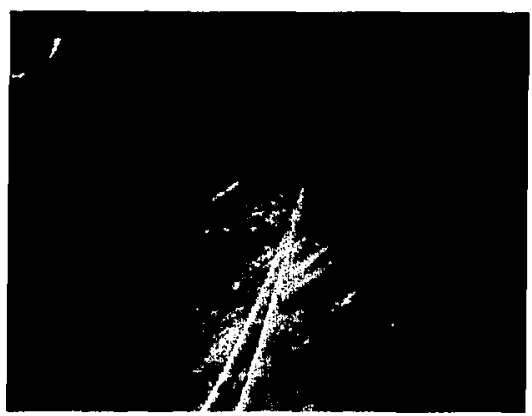

Fıg. 30 
The views of flow systems and their distinctive particulate matter are really shmin in three dimensions In the sense that the particle intensity and size are a function of the particle distance from the lens. To make precision measurements in this dimension we use a scanning microdensitometer. This system provides an $x-y-z$ view with the $z$ axis being light intensity and size measurement. The $\mathrm{x}$ and $\mathrm{y}$ are the physical dimensions of the display. This, with appropriate calibrations, allows us to measure the particle vectors within the observed volume (Figs. 31 , $32,33)$. The cursors, the bright lines on this display, allow us to set a point or line of calibrated measurement for particle-size determination. This also allows Integration of the total number of particles crossing the lines.

The short demonstrations in this tape 1llustrate droplets, bubbles and large drops, and the single and slow framing processes that can be used.

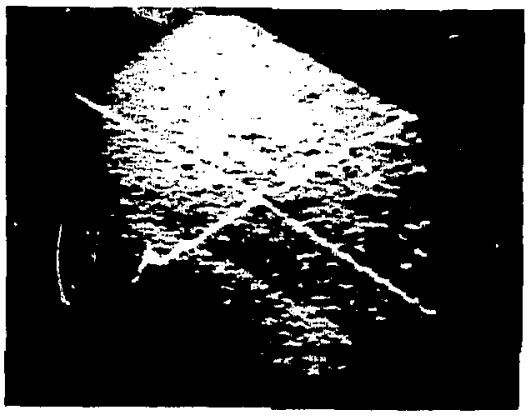

Fig. 31

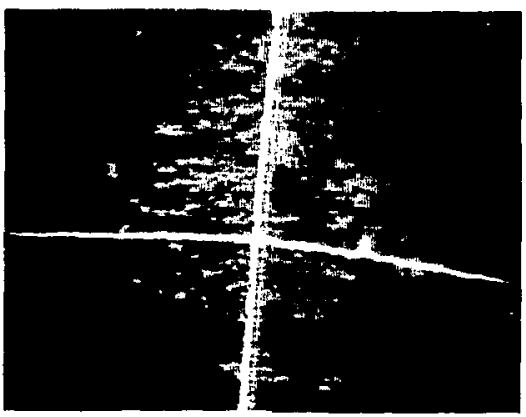

Fig. 32

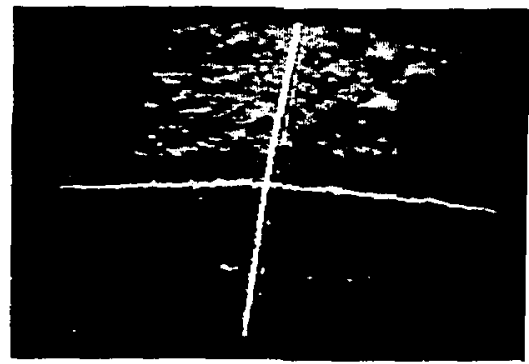

Fig. 33 
At the present time the basic rod lens has temperature and pressure 1Imitations. Continuous temperature Is about $180^{\circ} \mathrm{C}$ because of the lowmelting alloy seals and epoxy lens mounting. It appears that materials changes could Increase the continuousoperating temperature to $500^{\circ} \mathrm{C}$ or better. An alternative 18 to use an optlcal protective thermowe11. The pressure is now 1imited to several hundred ps1 (3-4 MPa). * However pressure is not a difficult problem because of the small size of the lens tube.

* We have aince tested the 5-mm lens to $17.5 \mathrm{MPa}$ external pressure without fallure.
There are limitations in resolution and framing rate imposed by the video system.

The standard video scan and the 30 frames $/ \mathrm{s}^{\dagger}$ rate can be improved for those applications that require it. However, the present systems make reasonably accurate measurements available now! In our opinion rod lenses coupled to low-11ght-1eve1 video systems have great application to many engineering measurement problems both static and dynamlc. Flow condition is one of these problems. The use of analytical electronics imaging systems for data processing is the additional link that allows us to put numbers on our observations.

$\dagger_{60} \mathrm{flelds} / \mathrm{s}$ on single field machines. 


\section{EPILOGUE}

Since this videotape was made we have procured a modified $44005 I T$ Cohu video camera that allows a fourfold increase in framing rate. It does this by reducing the vertical fleld of view and sweeping the smaller central area as many as four times during a standard frame. The camera is switchable from the standard full frame to two, three, and four smaller frames. Figures 3437 show the motion of a $2.54-\mathrm{cm}$ ball pendulum in each of the four framing options. The increased framing rate allows us to gage particle velocities and dynamic events with considerably greater precision than standard video systems. We are presently studying the interactions of the images of particles/missiles with the TV scanning system. Faster velocity

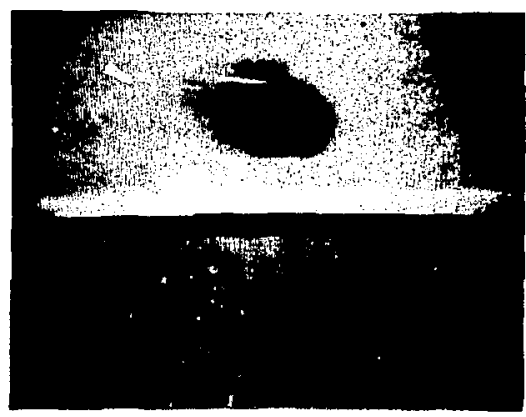

Fig. 35

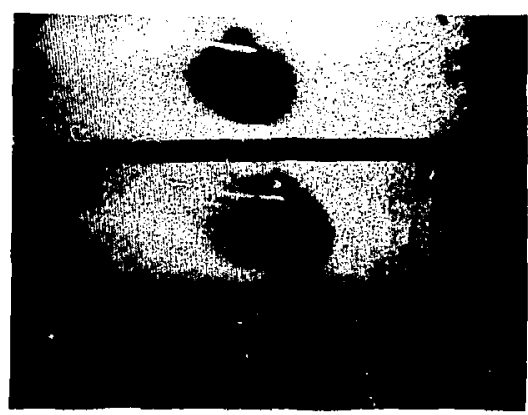

F1g. 36
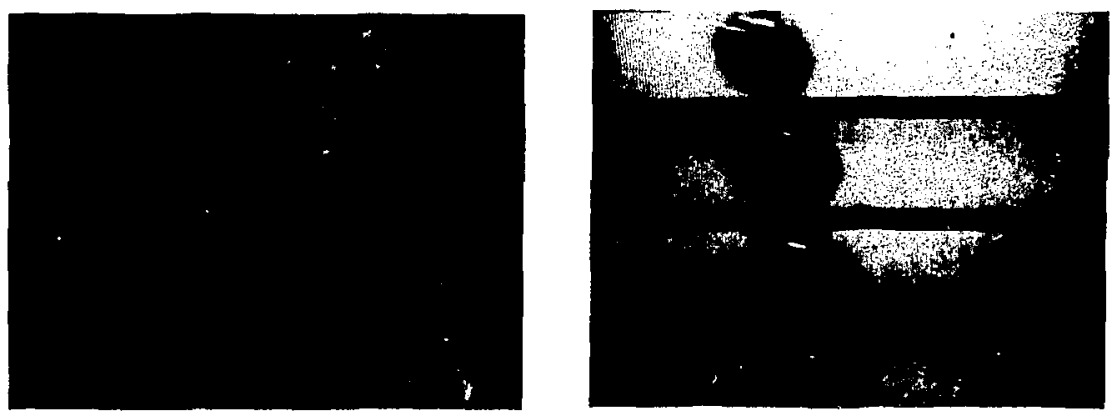

FIg. 34

Fig. 37 
measurements require interpretation dapending on slze, distance from the camera, and other factors.

We have also found that this rod lens low-1ight TV system can observe both dynamic combustion processes and active fabrication processes.

Coples of the original videotape may be obtained on a loan basts by concacting the authors, or permanent coples may be purchased through commerclal sources.

\section{ACKNOWLEDGMENTS}

Our sincere thanks are extended to Drs, John Pitts and Ed McCauley, and Vic Karpenko, all of LLL, whose early appreclation of this system contributed to its development. And most certaln1y to Drs. Tong, Fabic, Hsu, Slegers and McPhearson of the Nuclear Regulatory Commission whose Interest and support allowed this preliminary study to be made. 